\title{
Prototype Alat Olah Limbah Sistem Semi Batch Untuk Pengolahan Limbah Cair Laboratorium Kimia
}

\section{Prototype Of Liquid Waste Processing With Semi Batch Systems For Chemical Laboratory Liquid Waste Treatment}

\author{
Saipul Bahri ${ }^{*}$, Ade Yulia Astuti ${ }^{2}$ Ita Irawati $^{3}$, Mohammad Ryan Wahyudi ${ }^{4}$,Dhau Aprilia Hakim ${ }^{5}$, \\ Meta Aprilia Saputri ${ }^{6}$ \\ 1,2,3,4,5,6 Teknik Pengendalian Pencemaran Lingkungan, Politeknik Negeri Cilacap, Indonesia \\ *Email : 1'saipultekim2010@gmail.com, ${ }^{2}$ adeyulia2007@gmail.com, ${ }^{3}$ ita_irawati@gmail.com, \\ 4ryan.wahyudi@gmail.com, ${ }^{5}$ dhau.ah@gmail.com, ${ }^{6}$ apriliameta@gmail.com
}

Direview :5 Februari 2020

Direvisi :25 Februari 2020

\begin{abstract}
Abstrak
Limbah cair laboratorium kimia Teknik Pengendalian Pencemaran Lingkungan Politeknik Negeri Cilacap merupakan limbah cair yang berasal dari kegiatan praktik maupun penelitian dosen/mahasiswa. Sebagian besar limbah mengandung zat organik maupun anorganik yang berbahaya bagi lingkungan. Pada analisis awal didapatkan hasil kandungan air limbah berupa timbal <0,251 mg/L, Kesadahan 213,33 mg/L, TDS $4690 \mathrm{ppm}$, dan $\mathrm{pH}$ 1,6. Salah satu parameter yang perlu ditangani yaitu TDS karena padatan terlarut dapat memepengaruhi kadar $\mathrm{O}_{2}$ yang terkandung di perairan. Pada penelitian ini dibuat prototype alat olah limbah untuk melakukan pengolahan limbah tersebut. Dalam penelitian ini metode yang digunakan proses koagulasi, elektrokoagulasi dan sedimentasi secara batch dengan variasi waktu tinggal yang mempengaruhi produk. Selain itu prose filtrasi dan adsorpsi menggunakan sistim continue, sehingga secara keseluruhan alat ini menggunakan sistim semi batch. Pada penelitian ini bahan kimia yang digunakan untuk pengolahan berupa $\mathrm{CaCO}_{3}$ dan asam sitrat. Kemudian adsorben yang digunakan berupa zeolit dan arang aktif sebagai penjerap padatan terlarut. Alat pengolahan limbah ini dinilai cukup efektif dalam penurunan TDS dengan hasil akhir 2950 ppm.
\end{abstract}

Kata kunci: Laboratorium, Limbah cair, TDS

\section{Abstract}

Chemical laboratory liquid waste Environmental Pollution Control Techniques Cilacap State Polytechnic is liquid waste originating from practical or research activities of lecturers / students. Most of the waste contains organic and inorganic substances that are harmful to the environment. In the initial analysis the results of the wastewater content were in the form of lead $<0.251 \mathrm{mg} / \mathrm{L}$, Hardness $213.33 \mathrm{mg} / \mathrm{L}$, TDS 4690 ppm, and pH 1.6. One parameter that needs to be addressed is TDS because dissolved solids can affect the O2 levels contained in the waters. In this research, a prototype of a waste processing tool was used to process the waste. In this research the method used is the process of coagulation, electrocoagulation and sedimentation in batch with a variation of residence time which affects the product. In addition, the filtration and adsorption process uses a continuous system, so that overall the tool uses a semi-batch system. In this study the chemicals used for processing were $\mathrm{CaCO} 3$ and citric acid. Then the adsorbent used is zeolite and activated charcoal as absorbent of dissolved solids. This waste treatment tool is considered quite effective in reducing TDS with a final result of $2950 \mathrm{ppm}$.

Keywords: Laboratory, Liquid waste, TDS

DOI : 10.35970/jppl.v2i1.144

Corresponding Author : saipultekim2010@gmail.com 


\section{PENDAHULUAN}

Limbah cair laboratorium adalah limbah yang banyak mengandung senyawa organik dan anorganik. Limbah laboratorium merupakan sisa bahan kimia yang digunakan dalam aktivitas laboratorium. Limbah cair Laboratorium Teknik 
Pengendalian Pencemaran Lingkungan Politeknik Negeri Cilacap dikumpulkan dalam suatu wadah dan belum dilakukan pengolahan. Zat yang terkandung di dalam limbah cair laboratorium dalam kurun waktu yang lama apabila dibuang langsung ke lingkungan akan mencemari lingkungan, seperti merusak struktur tanah, mengancam kelangsungan hidup ekosistem baik di air maupun di darat, serta berdampak bagi kesehatan manusia (Aqil, Z., dkk, 2016). Oleh karena itu pada penelitian ini akan dibuat prototype alat pengolahan limbah cair Laboratorium Teknik Pengendalian Pencemaran Lingkungan Politeknik Negeri Cilacap.

Dari sisi jumlah, limbah cair yang dihasilkan oleh laboratorium memang relatif sedikit, namun karakteristik limbah yang dihasilkan cukup kompleks. Limbah cair laboratorium mengandung berbagai macam logam berbahaya dan dapat bersifat toksik bagi lingkungan. Selain logam berat, limbah cair laboratorium biasanya mengandung senyawa-senyawa organik yang juga bersifat toksik.

Pada penelitian ini akan dibuat prototype alat pengolahan limbah cair laboratorium kimia dengan sistem Semi Batch. Sistem semi batch merupakan sistem gabungan antara sistem kontinyu (pengolahan dengan pola aliran) dengan sistem batch (terdapat waktu tinggal). Beberapa proses pada metode pengolahan ini memiliki waktu tinggal yakni pada proses koagulasi, proses sedimentasi dan proses elektrokoagulasi dan metode lainnya berupa pengolahan kontinyu yakni proses filtrasi dan adsorbs (Raihan, R, 2018)

Bahan pengolahan limbah yang digunakan berupa bahan kimia dan bahan alam seperti pada proses koagulasi menggunakan $\mathrm{CaCO}_{3}$ dimana sifat basa dari kapur ini dapat bereaksi hebat dengan logam berat maupun dengan berbagai asam sehingga cocok dijadikan flokulan (Swasti, $\mathrm{N}$, dkk, 2018), proses filtrasi menggunakan batu, kerang, ijuk, proses elektrokoagulasi melibatkan peristiwa elektrolisis,proses sedimentasi, proses netralisasi menggunakan $\mathrm{C}_{6} \mathrm{H}_{8} \mathrm{O}_{7}$, proses adsorpsi menggunakan zeolit dan karbon aktif.

\section{METODE PENELITIAN}

\section{Prosedur Penelitian}

\section{a. Proses Perancangan Prototype}

Pembuatan prototype dimulai dengan proses pembuatan rangka dengan ukuran yang sudah ditentukan pada saat perancangan alat. Rangka terbuat dari kayu dengan tinggi 1,5 meter dan panjang \pm 2 meter. Setelah rangka terbentuk, tahapan selanjutnya yaitu menentukan dimensi penampungan untuk beberapa proses pengolahan yang digunakan. Air limbah yang terdapat pada box kontainer akan dipompa menuju box kontainer yang lain untuk dilakukan treatment proses koagulasi yang berupa proses penyerapan unsur bahan pencemar sehingga memebentuk flok-flok dengan waktu tinggal selama \pm 24 jam agar mendapatkan hasil yang maksimal. Flokulan yang digunakan berupa $\mathrm{CaCO}_{3} \pm 500$ gram. Air limbah yang sudah melewati proses koagulasi akan dialirkan melewati pipa ukuran 4 inch yang terdapat proses filtrasi.

Pada proses filtrasi tidak terdapat waktu tinggal, air limbah dari proses filtrasi akan mengalir secara langsung menuju bak elektroagulasi yang berkapasitas 20 liter. Proses elektrokoagulasi akan dibantu dengan menggunakan adaptor sebagai sumber listrik yang arus listriknya dilewatkan melalui plat alumunium. Arus listrik yang digunakan sebesar 3 amper dengan tegangan 12 volt.

Stop kran dipasang pada bak elektrokoagulasi agar aliran dapat diatur. Stop kran akan mengalirkan air limbah dari proses elektrokoagulasi menuju proses sedimentasi, pada proses ini air limbah membawa flokulan yang banyak sehingga memerlukan waktu tinggal selama \pm 3 jam untuk menjaga zat/flokulan yang masih melayang untuk dapat mengendap secara alami. Setelah waktu tinggal telah terlewati, air limbah akan dialirkan menuju bak absorpsi dengan 3 bahan adsorben yaitu $\mathrm{Al}_{2}\left(\mathrm{SO}_{4}\right)_{3}$, karbon aktif dan zeolit. Secara keseluruhan aliran pada prototype ini menggunakan teknik gravitasi yang mengalirkan cairan berdasarkan tinggi rendahnya level cairan dari permukaan.

b. Analisa Hasil Pengolahan Limbah Laboratorium

Pengambilan sampel untuk pengujian kualitas air limbah laboratorium dilakukan dua kali dengan waktu dan keadaan limbah yang berbeda yaitu tahap pertama dan tahap kedua. Tahap pertama, air limbah laboratorium sebelum proses atau air limbah awal. Tahap kedua yaitu air limbah setelah proses adsorpsi. Tahap kedua ini juga bisa disebut dengan air limbah akhir.

Uji kualitas air limbah pada penelitian ini menggunakan metode uji yang sesuai dengan peraturan yang telah ditetapkan yakni sesuai Standar Nasional Indonesia (SNI) bidang lingkungan kualitas air dan air limbah. Dengan parameter uji yang dibedakan menjadi dua kategori 
yaitu parameter uji fisika dan kimia. Parameter uji fisika yakni total dissolved solid (TDS) atau zat padat terlarut dan parameter uji kimia yakni $\mathrm{pH}$, kesadahan total dan kandungan timbal. Metode uji yang digunakan adalah:

a. Pengukuran $\mathrm{pH}$ dengan menggunakan $\mathrm{pH}$ meter digital.

b. Pengukuran TDS air limbah dilakukan dengan menggunakan alat konduktivitimeter

c. Pengukuran timbal menggunakan metode Spektrofotometri Serapan Atom (SSA)- Nyala, mengacu pada SNI.6989.8:2009.

d. Pengukuran kesadahan menggunakan metode titrimeti.- mengacu pada SNI 06-6989.12-2004.

Dari semua pengujian parameter, di dapatkan data yang dituangkan dalam bentuk tabel hasil pengujian. Untuk pengolahan data selanjutnya menggunakan perhitungan efisiensi penurunan polutan, dengan cara membandingkan hasil uji sebelum dan sesudah di lakukan proses. Proses pembandingan ini disebut Persentase penyisihan Polutan dengan satuan persentase $(\%)$.

\section{HASIL DAN PEMBAHASAN}

a. Hasil Perancangan

Pembuatan prototype alat ini pada dasarnya digunakan untuk mengurangi limbah cair yang berada di laboratorium prodi Teknik Pengendalian Pencemaran Lingkungan yang dihasilkan dari aktifitas laboratorium. Limbah yang dihasilkan termasuk limbah yang mengandung bahan berbahaya. Perancangan prototype ini dilakukan dengan mempertimbangkan metode yang efisien dalam mereduksi bahan berbahaya pada limbah cair tersebut. Metode yang digunakan antara lain yaitu proses flokulasi/koagulasi, proses filtrasi, proses elektrokoagulasi, proses sedimentasi dan proses adsorpsi. Berikut ini gambar prototype Alat pengolah limbah cair 

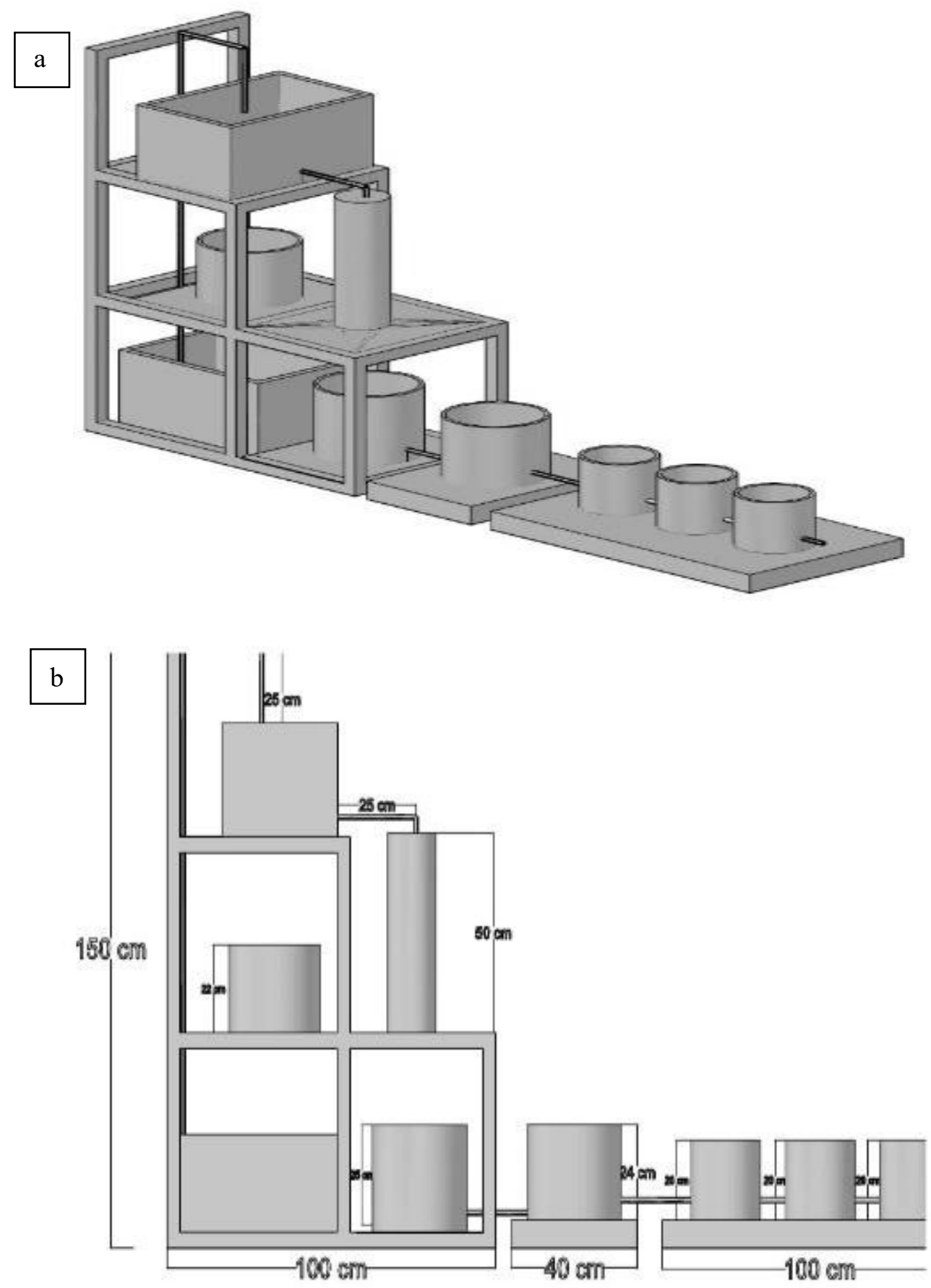

Gambar 1. Prototype Alat Pengolah Limbah Cair (a), Dimensi prototype Alat Olah Limbah (b)

\section{Pembahasan}

b. Analisa Luaran Produk

maran Lingkungan berasal dari berbagai kegiatan praktik mahasiswa maupun penelitian dosen/mahasiswa. Berbagai jenis bahan kimia yang digunakan pada aktifitas laboratorium akan

DOI : 10.35970/jppl.v2i1.144

Corresponding Author : saipultekim2010@gmail.com
Limbah cair laboratorium Teknik Pengendalian Pence

menjadi limbah cair kimia dengan karakteristik tersendiri. Beberapa bahan kimia yang digunakan pada aktivitas laboratorium antara lain $\mathrm{AgNO}_{3}$, $\mathrm{HCl}, \mathrm{NaOH}, \mathrm{H}_{2} \mathrm{SO}_{4}$, dan bahan-bahan kimia 
lainnya. Setelah dilakukan pengujian awal diketahui bahwa limbah laboratorium Teknik Pengendalian Pencemaran Lingkungan memiliki nilai TDS dan $\mathrm{pH}$ yang melebihi nilai baku mutu. Hasil analisis sampel awal dan akhir dapat dilihat pada Tabel 1:

Tabel 1. Hasil Analisi Awal dan Akhir Limbah Laboratorium Teknik Pengendalian Pencemaran Lingkungan

\begin{tabular}{|c|c|c|c|c|}
\hline Parameter & Satuan & $\begin{array}{c}\text { Nilai } \\
\text { Analisis } \\
\text { Awal }\end{array}$ & $\begin{array}{c}\text { Nilai } \\
\text { Analisis } \\
\text { Akhir }\end{array}$ & $\begin{array}{c}\text { Baku } \\
\text { Mutu } \\
\text { Gol.II }\end{array}$ \\
\hline $\mathrm{pH}$ & - & 1,6 & 7,5 & $6-9$ \\
\hline TDS & $\mathrm{Ppm}$ & 4690 & 2950 & 4000 \\
\hline Kesadahan & $\mathrm{mg} / \mathrm{L}$ & 213,33 & 460 & 500 \\
\hline Timbal & $\mathrm{mg} / \mathrm{L}$ & $<0,251$ & $<0,251$ & 1 \\
\hline
\end{tabular}

Sumber : Peraturan Mentri Lingkungan Hidup No 5 Tahun 2014

Data di atas menunjukkan bahwa dengan penggunaan koagulan $\mathrm{CaCO}_{3}$ dan proses elektrokoagulasi dapat memberikan hasil penurunan yang baik pada parameter TDS. Menurut Rahimah, dkk (2012) kapur lime dapat digunakan sebagai netralisasi $\mathrm{pH}$ secara alami karena sifat kapur yang basa dapat menetralkan limbah dalam suasana asam.

Limbah olahan yang keluar dari elektrokoagulasi masih dalam keadaan $\mathrm{pH}$ dan TDS diatas baku mutu. Nilai $\mathrm{pH}$ menunjukkan ada pada angka 11,9 dan TDS $4870 \mathrm{ppm}$. Hal ini diatasi dengan menambahkan penetral asam sitrat. Penelitian yang pernah dilakukan oleh Puspita dkk (2013) menyatakan bahwa asam sitrat $\left(\mathrm{C}_{6} \mathrm{H}_{8} \mathrm{O}_{7}\right)$ dapat dijadikan sebagai pengontrol $\mathrm{pH}$ serta menurunkan kadar kesadahan. Dimana asam sitrat memiliki kemampuan untuk menguraikan ion logam yang terkandung dalam air dengan tingkat kesahadan cukup tinggi, dengan demikian ion logam akan terakumulasi sebagai kompleks sitrat. Proses elektrokoagulasi dilakukan selama 3-5 jam. Pada proses ini terjadi peristiwa dekomposisi elektroloit, dimana ion positif (kation) bergerak menuju katoda dan menerima transfer elekton tereduksi kemudian ion negatif (anion) bergerak menuju anoda memberikan electron yang dioksidasi (Harsono, B., dkk, 2014). Ion $\mathrm{H}^{+}$dari suatu asam akan direduksi dan berubah menjadi hidrogen bebas dengan indikasi gelembunggelembung gas pada air limbah.

$$
2 \mathrm{H}^{+}+2 \mathrm{e} \longrightarrow \mathrm{H}_{2}
$$

Kemudian pelarut (air) dalam air limbah mengalami reduksi serta pembentukan gas

DOI : $10.35970 /$ jppl.v2i1.144

Corresponding Author : saipultekim2010@gmail.com hidrogen $\left(\mathrm{H}_{2}\right)$ pada katoda.

$$
2 \mathrm{H}_{2} \mathrm{O}+2 \mathrm{e} \longrightarrow 2 \mathrm{OH}^{-}+\mathrm{H}_{2}
$$

Adapun anoda yang digunakan berupa logam almunium (Al) dimana logam tersebut akan teroksidasi dengan reaksi sebagai berikut :

$$
\mathrm{Al}+3 \mathrm{H}_{2} \mathrm{O} \longrightarrow \mathrm{Al}(\mathrm{OH})_{3}+3 \mathrm{H}^{+}+3 \mathrm{e}
$$

Ion $\mathrm{OH}$ - yang berasal dari basa akan mengalami oksidasi sehingga membentuk gas oksigen $\left(\mathrm{O}_{2}\right)$,

$$
4 \mathrm{OH}^{-} \longrightarrow 2 \mathrm{H}_{2} \mathrm{O}+\mathrm{O}_{2}+4 \mathrm{e}
$$

Apabila larutan mengandung ion-ion logam lain maka ion-ion logam akan direduksi menjadi logamnya dan terdapat pada batang katoda.

$$
\begin{aligned}
& \mathrm{Li}^{+}+\mathrm{e} \longrightarrow \mathrm{L}, \\
\text { Contoh: } & \mathrm{Pb}^{2+}+2 \mathrm{e} \longrightarrow \mathrm{Pb}
\end{aligned}
$$

Berdasarkan reaksi daiatas maka pada anoda akan terbentuk gas, busa, dan flok $\mathrm{Al}(\mathrm{OH})_{3}$. (Harsono, B., $\mathrm{dkk}$, 2014). Proses elektrokoagulasi ini berhasil memberikan penurunan pada nilai TDS dengan angka $3770 \mathrm{ppm}$.

Air limbah kemudian dialirkan meuju bak sedimentasi dengan waktu tinggal \pm 3 jam. Sedimentasi ini bertujuan untuk mengendapkan flokulan maupun padatan terlarut yang terbawa dari proses sebelumnya. Dimana pada proses sebelumnya air limbah mengandung banyak busa serta flok-flok.

Kemudian dilakukan proses adsorpsi guna menurunkan kadar timbal dan menjerap partikelpartikel yang masih terlarut didalam air olahan. Adsorben yang digunakan berupa karbon aktif dan zeolit. Kedua adsorben ini memiliki pori-pori yang besar apabila ditingkatkan aktivasinya, dimana pori-pori yang ada di permukaan ini akan menjerap kadar logam maupun partikel terlarut yang ada pada air limbah. Luas pori-pori zeolit akan berpengaruh pada banyaknya adseorbat yang terjerap (Azamia, 2012 dalam Audiana, M., 2016). Salah satu fungsi zeolit yaitu menjerap logam timbal $\left(\mathrm{Pb}^{2+}\right)$. Ion logam $\mathrm{Pb}^{2+}$ akan terserap oleh pori-pori rataan zeolit dan bersubstansi dengan kation $\mathrm{H}^{+}$yang berada pada prataan zeoilit. Berikut reaksi yang terjadi :

$$
\begin{aligned}
& \text { Zeolit }-\mathrm{H}^{+}+\mathrm{Pb}^{2+} \longrightarrow \text { zeolit }-\mathrm{Pb}^{2+}+\mathrm{H}^{+} \\
& \text {(Audiana, M., 2016) }
\end{aligned}
$$

Reaksi di atas menunjukkan pertukaran antara ion logam $\mathrm{Pb}^{2+}$ dengan kation $\mathrm{H}^{+}$yang menyebabkan $\mathrm{Pb}^{2+}$ terperangkap di dalam pori-pori zeolit. Peristiwa ini disebabkan oleh permukaan silika $\left(\mathrm{SiO}_{2}\right)$ yang memiliki afinitas kuat terhadap elektron (mudah menangkap elektron). Ikatan yang dihasilkan oleh ion silika dan oksigen menjadikan rataan silika bersifat asam lemah. Lalu atom oksigen pada rataan silika bebas bereaksi dengan air membentuk kelompok silanol (SiOH). Bentuk oksida lainnya juga bebas bereaksi dengan air membentuk hidroksida. Ion $\mathrm{H}^{+}$pada bentuk 
hidroksida akan melemah dan mudah lepas serta mengakibatkan ion logam $\mathrm{Pb}^{2+}$ akan terikat dan terjerap secara kuat (Audiana, M., dkk 2016). Hal ini yang menyebabkan kadar timbal pada limbah menjadi turun. Sedangkan kation $\mathrm{H}+$ yang terdapat pada rataan zeolit terlepas dan menyebabkan $\mathrm{pH}$ air limbah bersifat asam.

Proses yang terakhir berupa sedimentasi hal ini bertujuan untuk mengontrol keadaan $\mathrm{pH}$ dan TDS akhir. Namun pada hasil akhir menunjukkan meningkatnya nilai kesadahan yang kemungkinan besar hal ini terjadi akibat dari kurangnya kereaktivan adsorben dalam menjerap logam maupun partikel yang ada pada air limbah. Kalsium yang terkandung dalam kapur juga ikut larut dalam air olahan sehingga menjadikan nilai kesadahan meningkat.

\section{KESIMPULAN DAN SARAN}

Kesimpulan dalam penelitian ini pembuatan prototype ini bertujuan untuk melakukan pengolahan limbah laboratorium dengan skala kecil. Selain itu, alat olah limbah ini dinilai efektif dalam penurunan TDS dengan nilai awal sebesar $4690 \mathrm{mg} / \mathrm{L}$ menjadi $2950 \mathrm{mg} / \mathrm{L}$. Output air yang sudah diolah memiliki $\mathrm{pH}$ yang normal dan sesuai baku mutu dengan nilai pH sebesar 7,5.

Adapun saran pada penelitian selanjutnya sebagai berikut :

1. Sebelum perancangan disarankan agar peneliti dapat merinci biaya supaya lebih efisien serta merencanakan desain yang lebih praktis untuk mempersingkat waktu pembuatan.

2. Perlunya aktivasi yang tepat pada adsorben agar cara kerjanya lebih baik dalam menjerap polutan.

3. Homogenisasi saat proses koagulasi sangat berpengaruh pada pembentukan flok dalam air limbah, dimana pengadukan dilakukan secara perlahan agar tidak memecah ikatan yang telah terjadi dan tidak terlalu pelan agar antar partikel saling mengikat.

\section{UCAPAN TERIMA KASIH}

Penulis mengucapkan terimakasih kepada pihak kampus Politeknik Negeri Cilacap yang telah memfasilitasi pembuatan prototype alat pengolahan limbah cair laboratorium ini. Serta ucapan terimakasih kepada pihak-pihak terkait lainya yang telah membantu menyelesaikan proses penelitian ini.

\section{DAFTAR PUSTAKA}

Artiyani A, Firmansyah N.H.2016. Kemampuan Filtrasi Upflow Pengolahan Filtrasi Upflow

DOI : 10.35970/jppl.v2i1.144

Corresponding Author : saipultekim2010@gmail.com
Dengan Media Pasir Zeolit dan Arang Aktif Dalam Menurunkan Kadar Fosfat dan Deterjen Air Limbah Domestik. Jurnal Industri Inovatif. 6 (1), 8 - 15.

Audiana, M., Apriani, I., Kadaria U. 2016 Pengolahan Limbah Cair Laboratorium Teknik Lingkungan Dengan Koagulasi Dan Adsorpsi Untuk Menurunkan COD, Fe, DAN Pb. https://www.neliti.com/id/publications/190 757/pengolahan-limbah-cair-

laboratorium-teknik-lingkungan-dengankoagulasi-dan-adsor. 10 Januari 2020

Azamia, M. 2012. Pengolahan Limbah Cair Laboratorium Kimia Dalam Penurunan Kadar Organik Serta Logam Berat Fe, Mn, $\mathrm{Cr}$, Dengan Metode Koagulasi Dan Adsorpsi. Skripsi. Universitas Indonesia.

Balai Riset dan Standardisasi Industri Palembang. (2011). Pengolahan Air Limbah Laboratorium Terpadu Dengan Sistem Kontinyu. Jurnal dinamika penelitian industri vol. 22 no. 2 Tahun 2011.

Aqli, Z., Banda, K., Fadillah, N., Hermawan, Ardy., Nikara, T., Suprianto, Syahril. 2016. Proposal Penelitian Pengolahan Air Limbah Cair (Domestik) Pada Instalasi Pengolahan Limbah Cair._STUDI KASUS IPAL MARGASARI Tahun 2016.

Harsono, B., Makmur A., Pangputra R., Wiyanto E. 2014. Penerapan Elektrokoagulasi Dalam Proses Penjernih Limbah Cair. Jurnal Ilmiah Teknik Elektor. Vol. 12 No. 1 : Halaman 19 - 36

Peraturan Mentri Lingkungan Hidup No 5 Tahun 2014.

Puspita, C Y, Melinda V, Hadba, A N, Poly, D C. 2013. ASAM SITRAT. http://makalahbioproses.blogspot.com/201 3/06/makalah-bioproses-asamsitrat.html? $m=1$. 10 Januari 2020

Rahimah, Z, Heldawati, H, Isna Syauqiah. 2016. Pengolahan Limbah Deterjen Dengan Metode Koagulasi flokulasi Menggunakan Koagulan Kapur Dan PAC. Konversi. 5(2), 13-19.

Raihan, R, 2018. Alat Reaktor. http://myteknikkimiablogaddress.blogspot. com/2018/01/alat-reaktor.html $? m=1 . \quad 31$ Januari 2020.

Saswita, N., Sulistiyani., Setiani, O. 2017. Penggunaan Kapur Tohor $(\mathrm{CaO})$ Dalam Penurunan Kadar Logam Fe Dan Mn Pada Limbah Cair Pewarnaan Ulang Jeans Kabupaten Magelang Tahun 2017. Jurnal Kesehatan Masyarakat. Vol. 6 No. 1 : Halaman $662-669$. 
Jurnal Pengendalian Pencemaran Lingkungan (JPPL)

Vol.2 No.01 Maret 2020

DOI : 10.35970/jppl.v2i1.144

Corresponding Author : saipultekim2010@gmail.com 